\title{
Erratum to: Systematic evaluation of bone dysplasias by the paediatric radiologist
}

\author{
A. E. Oestreich
}

Published online: 10 June 2010

(C) Springer-Verlag 2010

Erratum to: Pediatr Radiol

DOI 10.1007/s00247-010-1594-x

In the Conclusion section, 1st paragraph on page 977 third last line the words "Bowdler-spur curved long bone in hypochondroplasia..." should read as follows:

Bowdler-spur curved long bone in hypophosphatasia

The online version of the original article can be found at http://dx.doi. org/10.1007/s00247-010-1594-x.

A. E. Oestreich $(\bowtie)$

Radiology Department, 5031 Cincinnati Children's Hospital,

Medical Center,

3333 Burnet Ave,

Cincinnati, OH 45220-1135, USA

e-mail: alan.oestreich@cchmc.org 